Jefferson University. The ability to have stakeholders at the table, with the sole mission of saving life and reducing disability, exemplifies the importance of strengthening research partnerships in a health care system. Our injury science experts devote themselves to conducting research, providing education, engaging social entrepreneurship and partnering with communities in the Delaware Valley and beyond. The aim of this Strengths, Weaknesses, Opportunities, and Threats (SWOT) analysis is to evaluate the effectiveness of an injury-based research partnership within an academic, medical and trauma center.

Methods/Approach The constant monitoring and a periodic review and reformation of health systems are of fundamental importance in all countries of the world, in order to increase the efficiency and effectiveness of healthcare services delivery, quality, equity, and sustainable financing (Han, 2012). To identify the SWOT of JCIRP a thorough analysis was completed by the center's leadership and stakeholders. Through this analysis, facilitators and barriers were identified that helped cultivate the growth of our research center.

Results Analyzation of the SWOT analysis identified four prominent themes. The accessibility of multidisciplinary professionals with a common interest of injury research and prevention and continued opportunities to enhance research partnerships in various disciplines at Jefferson was a commonality. The demonstration of return of investment in injury prevention research and advocacy and the controversial nature of violence prevention research in an ICRC were identified barriers to the successful implementation of an ICRC.

Conclusion The benefits of interdisciplinary partnerships and the investment of enterprise support are integral for the success of an ICRC.

Significance and Contribution Strengthening research partnerships in an ICRC through various disciplines will afford us the opportunity to continue injury prevention research.

\section{ASSOCIATION BETWEEN GUN OWNER ATTITUDES AND THEIR BEHAVIOR IN PRIVATE FIREARM SALES}

Molly Merrill-Francis, Emma Beth McGinty, Colleen Barry, Daniel Webster, Cassandra Crifasi. Johns Hopkins Bloomberg School of Public Health

\subsection{6/injuryprev-2020-savir.105}

Statement of Purpose Federal government only regulates individuals 'in the business' of selling firearms, leaving private firearm sales unregulated unless action is taken at the state level. Private sellers are less likely than licensed dealers to conduct background checks and most guns used in crime originate from sales in unregulated markets. This study examines whether private sellers' attitude that it is the responsibility of a seller to ensure buyers passed a background check prior to making a sale is associated with them checking purchasers for eligibility on their last sale.

Methods/Approach This study uses data from a nationally representative, web-based survey of 1,444 individuals who personally owned guns. Respondents who self-reported participating in the private market $(\mathrm{N}=238)$ were asked whether they had ensured purchasers were eligible to buy a firearm on their last private sale. Respondents were also asked to rate the extent to which they agreed it was a seller's responsibility to ensure purchasers had passed a background check. Logistic regression was used to test for differences in behaviors based on sellers' perception of responsibility for ensuring purchaser eligibility.

Results Just $44 \%$ of respondents checked purchasers for eligibility on their last private sale. Less than half (46\%) of private sellers agreed that it is seller responsibility to ensure purchasers passed a background check. Agreement was significantly associated with reporting ensuring purchasers were eligible to own a firearm on their last private sale $(58 \%$ to $36 \%)$.

Conclusion A low number of background checks in the private market are occurring. Increasing sellers' feelings of responsibility may increase background and permit checks in the private market.

Significance and Contributions to Injury and Violence Prevention Science Our findings suggest that programs or campaigns to increase private sellers' feelings of responsibility may increase the number of background checks conducted in the private market.

\section{THE USE OF HOSPITAL DISCHARGE DATA TO COUNT SEXUALLY EXPLOITED YOUTH AND YOUNG ADULTS IN MINNESOTA}

1,2Linzi Zhu, ${ }^{1} J o n$ Roesler, ${ }^{1}$ Beatriz Menanteau, ${ }^{1}$ Mark Kindemark. ${ }^{1}$ Minnesota Department of Health; ${ }^{2}$ University of Minnesota

10.1136/injuryprev-2020-savir.106

Statement of Purpose The Minnesota Department of Health $(\mathrm{MDH})$ human trafficking prevention Safe Harbor Program provides services to commercially sexually exploited youth and young adults through age 24 (SEY), as well as those at risk of being sexually exploited. SEY is a form of sexual violence and of human trafficking (HT). Hospitals can be an effective intervention point for violence prevention as well as a referral base for services, including the Safe Harbor Program. Child sexual violence (CSV) is an important risk factor for SEY. While there have been ICD-10-CM diagnostic codes for CSV, codes specific to HT, including SEY, were introduced in October of 2018. This research examines how these codes might be used to better identify, describe, serve, and possibly refer hospital-treated SEY and CSV victims for services.

Method/Approach Using statewide hospital discharge data and the Safe Harbor service data as a reference, $\mathrm{MDH}$ examined the ICD-10-CM codes for CSV from 2016 to 2018, as well as the new HT codes from the start of FFY2019.

Results The CSV codes identified 936 patients who were Minnesota residents ages 10-24: 63 males and 873 females. Preliminary data analysis of FFY2019 identified 23 HT patients, reported from 8 of Minnesota's $130+$ hospitals. These patients included three males and 20 females, including nine Safe Harbor service eligible cases.

Conclusion Epidemiologists now have the opportunity to effectively partner with service providers, counting what they could not count before. Moreover, hospitals can directly refer hospital-treated SEY and CSV (at-risk for SEY) to resources, such as the Safe Harbor Program.

Significance This is the first study using hospital discharge data with the new human trafficking ICD-10-CM codes to address SEY, as well as providing a descriptive epidemiology of hospital-treated CSV cases describing youth and young adults at risk for SEY. 